\title{
Improving Corrosion Resistance of AZ31B Magnesium Alloy via a Conversion Coating Produced by a Protic Ammonium-Phosphate Ionic Liquid
}

\author{
Hassan H. Elsentriecy ${ }^{1,2}$, Jun $\mathrm{Qu}^{1,{ }^{1,}}$, Huimin Luo ${ }^{3}$, Harry M. Meyer $\mathrm{III}^{1}$, Cheng Ma ${ }^{1}$, Miaofang $\mathrm{Chi}^{1}$ \\ ${ }^{1}$ Materials Science and Technology Division, Oak Ridge National Laboratory, TN, USA \\ ${ }^{2}$ Central Metallurgical Research and Development Institute, Cairo, Egypt \\ ${ }^{3}$ Energy and Transportation Science Division, Oak Ridge National Laboratory, TN, USA
}

\begin{abstract}
Magnesium alloys are susceptible to corrosion because of their high reactivity and low electrode potential. The present work introduces a conversion coating using a protic ammonium-phosphate ionic liquid (IL). Initial results on the $\mathrm{Mg}$ AZ31B alloy have demonstrated substantially improved corrosion resistance for the IL treatment at $300{ }^{\circ} \mathrm{C}$ (IL_300C) compared to the treatment at room temperature. Potentiodynamic polarization analysis of the IL_300C treated Mg surface in a $\mathrm{NaCl}$ solution exhibited a strong passivation behavior. No pretreatment is needed and the treated surface morphology is well preserved. Cross-sectional nanostructure examination using transmission electron microscopy and element mapping using energy-dispersive X-ray spectroscopy have revealed the IL_300C conversion coating to be a $70-80 \mathrm{~nm}$ thick with a twolayer structure. Further surface chemical analysis using X-ray photoelectron spectroscopy suggested such an IL conversion coating possibly composed of metal oxides, metal phosphates, and carbonaceous compounds.
\end{abstract}

Keywords: magnesium; corrosion; conversion coating, protic ammonium-phosphate ionic liquid

\footnotetext{
"P.O. Box 2008, MS-6063, Oak Ridge, TN 37831-6063, Tel: (865) 576-9304, E-mail: qujn@ornl.gov 


\section{Introduction}

Magnesium (Mg) alloys are of growing engineering interest to the aerospace and automotive industries because of their high specific strength and low density. However, $\mathrm{Mg}$ alloys have high corrosion susceptibility due to Mg's low Reduction Potential, $E^{\circ}=-2.37 \mathrm{~V}$ vs. NHE [1] and thus their use in engineering applications has been limited. The corrosion behavior of $\mathrm{Mg}$ alloys has been thoroughly reviewed by Song and Atrens [2-5]. The corrosion damage can be generally categorized into galvanic corrosion, intergranular corrosion, stress corrosion cracking, corrosion fatigue, etc. Corrosion prevention for Mg alloys may be achieved by various coating techniques such as chemical conversion coatings, electro- or electroless metal plating, anodizing, gas-phase deposition processes, organic and organic-inorganic coatings, and hydride coatings [1-8]. Traditional conversion coatings are based on hexavalent chromium compounds, which are currently being phased out due to the associated severe environmental risks. Chromate-free conversion coatings [9] using stannate [10, 11], rare earth elements, aluminum, zirconium, niobium, zinc phosphate, or phosphate permanganate are currently in early stages of development and have been reported to retard corrosion of $\mathrm{Mg}$ alloys to various extents. Particularly, phosphate salts are of great interest because of their low environmental risks and good performance in forming conversion coatings for paint preparation of magnesium alloys [12$14]$.

Ionic liquids (ILs) [15] are, as the name indicates, composed solely of cations and anions (see Fig. 1) instead of neutral molecules. They are primarily used as "green" solvents in chemical synthesis, electrochemistry, and catalysis, due to their ultra-low vapor pressure, nonflammability, high thermal stability, and flexible molecular structures. Very limited research in the recent literature (primarily from Forsyth's group [16-22]) suggests that the corrosion of $\mathrm{Mg}$ 
alloys may be retarded when the magnesium surfaces were exposed to ILs, either at room temperature [16-20] for an extended period, heated at a moderate temperature $\left(50{ }^{\circ} \mathrm{C}\right)[18]$, or with electrical potential bias [21,22]. It is believed that the improved corrosion resistance was attributed to the formation of a conversion film that is often heterogeneous with substantial buildup adjacent to grain boundaries $[19,20]$. The conversion film formation mechanisms are, however, not yet fully understood. Three possible mechanisms of IL-Mg interactions were proposed in this literature [19]: (1) physical adsorption by electrostatic attraction of the IL species (anions and cations) and formation of a double layer on the metal surface, (2) the anion of the IL chemically reacts with the metal ions dissolved during the immersion process, and (3) anion and/or cation electrochemically breaking down to new species that then react with the $\mathrm{Mg}$ surface. Surface chemical analysis supported the third one while little evidence was observed for the first and second [19].

We hypothesize that the Mg surface conversion coating formed in an IL is a result of a series of chemical reactions involving ion breakdowns with the decomposition products reacting with the metal surface. Furthermore, we believe that the conversion coating formation is not limited to electrochemical processes suggested in [19] but can be excited by other energy forms as well, such as thermal and/or mechanical stresses. This was in part inspired by observations in our previous research in IL lubrication, in which we revealed that IL ions tend to break down under the thermal (frictional heating) and mechanical (normal and shear) stresses and then react with the metallic surfaces to form protective boundary films during the wear process $[23,25]$. These findings have led us to study the application of ILs to the Mg surface at an elevated temperature to form a conversion coating for corrosion protection. The thermal stress is expected to promote a more effective conversion coating formation compared to previous work that involves extended 
ILs exposure at either room or mild $\left(50{ }^{\circ} \mathrm{C}\right)$ temperature [11-15]. In our initial effort [26], an aprotic IL, tetraoctylammonium di(2-ethylhexyl)phosphate, was used in the conversion treatment at $300{ }^{\circ} \mathrm{C}$, which however required phosphoric acid pickling to activate the $\mathrm{Mg}$ surface to gain an effective corrosion protection. One drawback of the pickling process is roughening and discoloring the $\mathrm{Mg}$ surface.

Here we present the results of using a protic IL trioctylammonium di(2ethylhexyl)phosphate ([N $\left.\left.\mathrm{N}_{888} \mathrm{H}\right][\mathrm{DEHP}]\right)$ to form an effective anti-corrosion conversion coating for the AZ31B Mg alloy at an elevated temperature with no need of a pretreatment. This may be attributed to the protic ammonium cation of $\left[\mathrm{N}_{888} \mathrm{H}\right][\mathrm{DEHP}]$ that readily donates protons $\left(\mathrm{H}^{+}\right)$, similar to a weak acid, to activate the Mg surface during the treatment. The protic IL-treated $\mathrm{Mg}$ surface had literally no appearance or morphology change. Advanced surface characterization techniques including transmission electron microscopy (TEM), energy-dispersive X-ray spectroscopy (EDS), and X-ray photoelectron spectroscopy (XPS) were used to investigate the IL conversion coating and corrosion protection mechanism.

\section{Experimental}

\subsection{Materials and surface preparation}

The Mg alloy used in this study was a wrought AZ31B, kindly provided by Magnesium Elektron North America, MENA. Chemical composition of this alloy was determined by inductively coupled plasma atomic emission spectroscopy at DIRATS Laboratories, Westfield, MA, USA, as shown in Table 1. 
Block (25.4 mm x $19.05 \mathrm{~mm} \times 6.35 \mathrm{~mm})$ and disk (15 mm diameter x $3 \mathrm{~mm}$ thickness) samples were cut and the test surfaces were ground using SiC abrasive paper up to P2400. The samples were then cleaned with acetone and deionized water (DI) and dried with air stream.

The IL used was trioctylammonium di(2-ethylhexyl)phosphate ([ $\left.\left.\mathrm{N}_{888} \mathrm{H}\right][\mathrm{DEHP}]\right)$. As illustrated in Fig. 1, the protic IL was synthesized by neutralization through a combination of equal molar amounts of trioctylamine $(2.37 \mathrm{~g}, 6.69 \mathrm{mmol})$ and Di (2-ethylhexyl) phosphoric acid (HDEHP, $2.16 \mathrm{~g}, 6.69 \mathrm{mmol}$ ) at room temperature for 2 hours. The mixture became more viscous upon stirring. The water content of the IL was 980 ppm. Mass spectrometry (MS) analysis confirmed the cation and anion chemistry. MS (ESI positive) $\mathrm{m} / \mathrm{z}=354.41$ (calculated 354.41 for $\left[\mathrm{C}_{24} \mathrm{H}_{52} \mathrm{~N}\right]^{+}$) and $\mathrm{MS}$ (ESI negative), $\mathrm{m} / \mathrm{z}=321.23$ (calculated 321.22 for $\left.\left[\mathrm{C}_{16} \mathrm{H}_{34} \mathrm{PO}_{4}\right]^{-}\right)$.

Thermogravimetric analysis (TGA) was conducted on $\left[\mathrm{N}_{888} \mathrm{H}\right][\mathrm{DEHP}]$ using a TA Instruments $\mathrm{TGA}-2950$ at a $10^{\circ} \mathrm{C} / \mathrm{min}$ heating rate in both nitrogen and air environment and results are shown in Fig. 2. There is little difference between the two TGA curves and the onset decomposition temperature is $\sim 235^{\circ} \mathrm{C}$.

The Mg alloy surface was treated by applying a layer of $\left[\mathrm{N}_{888} \mathrm{H}\right][\mathrm{DEHP}]$ to the sample surface and then heat treated at $300{ }^{\circ} \mathrm{C}$ in a furnace for $7 \mathrm{~min}$ (denoted as: IL_300C). The treatment temperature $300{ }^{\circ} \mathrm{C}$ was selected to ensure rapid decomposition of the IL (see the TGA curve in Fig. 2) during the heating process. After the heat treatment, the sample surface was cleaned by ethanol in an ultrasonic cleaner and dried with a stream of air. For comparison, another sample was treated similarly but at room temperature (RT) for 24 hours (denoted as: IL_RT). A third sample heat-treated at $300{ }^{\circ} \mathrm{C}$ without application of the IL (denoted as: As polished_300C) to elucidate the role of the IL in changing the corrosion resistance. 


\subsection{Surface characterization}

The morphology and chemical composition of the coated surfaces were characterized using a scanning electron microscope (SEM) with an energy dispersive x-ray (EDS) analysis unit (Hitachi S-4800 Field Emission SEM), cross-sectional transmission electron microscopy (TEM) examination and X-ray photoelectron spectroscopy (XPS) chemical analysis. TEM samples were prepared using a FEI Nova 200 Dual-beam Focused Ion Beam (FIB) System with a Ga source to extract a thin cross-section of the near-surface zone from the IL-treated surface. A carbon film and then a tungsten layer were deposited on the sample surface prior the FIB process to protect the tribo-film. The TEM system was a Hitachi ${ }^{\mathrm{TM}}$ HF-3300 TEM/STEM equipped with a Bruker solid state EDS detector. XPS analysis was carried out on a Thermo Scientific K-Alpha XPS instrument. The $\mathrm{x}$-rays used were monochromatic $\mathrm{Al}-\mathrm{k}_{\alpha}$ photons and photo-emitted electrons were analyzed with a hemispherical energy analyzer. Wide survey scans were collected from 0 $1350 \mathrm{eV}$ at a pass energy of $200 \mathrm{eV}$ to determine overall elemental composition. The K-Alpha energy resolution is adequate at a pass energy of $200 \mathrm{eV}$ and is, in fact, the default setting for survey scans (pass energy does not equal resolution). The composition of the survey scan is always checked against the composition determined by narrow region core level spectra as a "double check". Surface compositions were calculated by measuring peak areas of the primary core levels for all elements present and normalizing the peak areas using tabulated sensitivity factors. Depth profiling was done using a $3 \mathrm{kV}$ Ar-ion sputter beam rastered over an area $1 \times 2$ $\mathrm{mm}$. The base pressure in the analysis chamber was about $10^{-9} \mathrm{~Pa}$. All depth profiles were collected using identical ion gun conditions so that profiles can be compared. Previous measurements on standard $\mathrm{SiO} 2$ films gave a sputter rate of $\sim 15 \mathrm{~nm} / \mathrm{min}$ for these ion gun conditions. 


\subsection{Electrochemical and immersion corrosion tests}

Electrochemical corrosion tests were performed using the potentiodynamic polarization technique. In these tests, the alloy samples were polarized at potentials from -300 to $+600 \mathrm{mV}$ vs. OCP (open circuit potential) at a scanning rate of $0.166 \mathrm{mV} / \mathrm{s}$ in aerated conditions at room temperature. The test solution was 1 wt.\% $\mathrm{NaCl}$ saturated with $\mathrm{Mg}(\mathrm{OH})_{2}(0.25 \mathrm{~g} / \mathrm{l})$. Saturated magnesium hydroxide was used to ensure a stable $\mathrm{pH}$ value of the solution near the metal surface during the testing process. The $\mathrm{pH}$ of the test solution was measured before and after the measurements and it was almost constant $(\mathrm{pH}=10.80 \pm 0.2)$ for all electrochemical measurements conducted in this study. A three-electrode electrochemical cell was used. A Pt sheet $(25 \mathrm{~mm} \times 25 \mathrm{~mm} \times 0.2 \mathrm{~mm})$ was used as a counter electrode and $\mathrm{Ag} / \mathrm{AgCl}(4 \mathrm{M} \mathrm{KCl}$ internal solution) as a reference electrode and a disk AZ31B sample with $1 \mathrm{~cm}^{2}$ exposed area as a working electrode. All electrochemical tests were conducted using a Princeton Applied Research (PARSTAT 4000, Potentiostat/Galvanostat/EIS Analyzer). The sample to be tested was immersed for $30 \mathrm{~min}$ in $700 \mathrm{ml}$ of the test solution before starting the experiment. Experiments were repeated three times to ensure reproducibility of the experimental results. The corrosion current densities $\left(\mathrm{I}_{\text {corr }}\right)$ were determined from polarization curves using VersaStudiov2.10.4412. In the software a potential range of $\pm 250 \mathrm{mV}$ vs. OCP was used to determine the $\mathrm{I}_{\text {corr }}$ (Tafel fit).

To investigate the effect of corrosive solution on the IL conversion film, the sample treated by the IL at $300{ }^{\circ} \mathrm{C}$ was immersed in 1 wt. $\% \mathrm{NaCl}$ saturated with $\mathrm{Mg}(\mathrm{OH})_{2}$ for 4 hours. XPS analysis was conducted on this sample before and after the exposure to the corrosive solution. Table 2 lists the Mg samples investigated in this study. 


\section{Results and discussion}

\subsection{Electrochemical corrosion tests}

Figure 3a shows representative potentiodynamic polarization curves of the four Mg samples 'As polished', 'As polished_300C', 'IL_RT', and 'IL_300C' in 1 wt.\% $\mathrm{NaCl}$ saturated with $\operatorname{Mg}(\mathrm{OH})_{2}$. (The curve of the baseline, as-polished AZ31B sample, has been reported in our previous work [26].) To demonstrate the test repeatability, Fig. 3b shows the repeated runs of IL_300C. Tests on other samples had good repeatability as well but detailed results are not shown here. It can be observed that the resistance to pitting corrosion of the Mg surface treated by the protic IL at $300{ }^{\circ} \mathrm{C}$ (IL_300C) is significantly higher than that of the untreated (bare) surface (As polished, heat-treated surface without IL (As polished_300C), or IL-treated surface at RT (IL_RT). This was evidenced by the apparent passivation and barrier behavior (i.e. increased polarization potential with almost constant anodic current) for the IL_300C sample. In contrast, such passivation does not exist for As polished or As polished_300C, and is much weaker for IL_RT. Results in Fig. 3a suggest that the thermal stress under the elevated temperature likely promoted the IL decomposition and interactions with the Mg alloy surface to form a conversion coating with enhanced anti-corrosion characteristics. Unlike an aprotic ammonium-phosphate IL that requires acid pickling to activate the Mg surface [26], this protic IL forms an effective conversion film without any pretreatment. This may be attributed to the protic ammonium cations that readily donate protons $\left(\mathrm{H}^{+}\right)$, like a weak acid, to activate the $\mathrm{Mg}$ surface.

The corrosion parameters deduced from the polarization curves in Fig. 3a are summarized in Table 3. The IL_300C sample had the lowest corrosion current density (indication of lower corrosion rate) among the other tested samples. In addition and most importantly, the IL_300C 
sample showed a higher positive pitting potential $\left(\mathrm{E}_{\mathrm{pit}}\right)$ than that of IL_RT sample. The pit nucleation resistance (the resistance to pitting initiation) measured by the difference between pitting potential and corrosion potential $\left(\mathrm{E}_{\mathrm{pit}}-\mathrm{E}_{\mathrm{corr}}\right)$ evidently indicates that the pitting corrosion resistance of the IL_300C sample is $\sim 5 \mathrm{X}$ higher than that of the IL_RT sample. The IL treatment at the elevated temperature resulted in a higher resistance to the corrosion attack of aggressive ions such as $\mathrm{Cl}^{-}$ions.

\subsection{SEM surface morphology examination}

Figure 4 presents SEM images of the as polished and IL_300C treated Mg AZ31B surfaces, which clearly show that the conversion treatment using the protic IL did not induce any noticeable change to the surface appearance or morphology. This is another advantage of using a protic ammonium-phosphate IL over an aprotic IL [26] that requires a pickling pretreatment causing a roughened and discolored surface.

\subsection{Cross-sectional TEM examination and EDS elemental mapping}

Figure 5 shows a cross-sectional TEM image and EDS element maps of the near surface zone

of the IL_300C surface. A surface film was discovered in a two-layer (duplex) structure with a total thickness of $70-80 \mathrm{~nm}$. It is likely that the clear-cut interface between the two layers was the original alloy surface before the IL treatment. Both layers are rich in $\mathrm{Mg}, \mathrm{O}, \mathrm{P}$, and $\mathrm{N}$. The top layer $(30-35 \mathrm{~nm})$ was probably formed by the metallic atoms that diffused out of the surface reacting with the decomposed IL species and oxygen. The second layer seems to be a result of reactions between the alloy elements and the IL species and oxygen that diffused into the metal surface. 


\subsection{XPS surface chemical analysis}

To further characterize the conversion coating on the IL_300C surface, XPS chemical analysis was conducted before and after exposure to a corrosion solution, i.e. IL_300C and IL_300C_corr, as defined in Table 2.

Table 4 shows the XPS survey data for the IL_300C and IL_300C_corr samples. The phosphorus content on the IL_300C surface, originated from the IL, indicates interactions occurred between the IL and the alloy surface. The IL_300C surface contains $>30$ at.\% oxygen suggesting considerable oxidation during the coating process. The little $\mathrm{P}$ content after the corrosion test (IL_300C_corr) implies that the conversion coating actively interacted with the salt solution and was eventually dissolved during the corrosion process.

The XPS core level spectra of major elements collected from the IL_300C and IL_300C_corr surfaces are shown in Fig. 6. Likely bonding is labeled on each major peak based on [27, 28]. Peaks of $\mathrm{Mg}, \mathrm{Al}, \mathrm{P}$ and $\mathrm{O}$ suggest that oxides and phosphates are dominant. The general binding energy of $\mathrm{P} 2 \mathrm{p}$ is in the range of $133-134 \mathrm{eV}$ indicating P-O bonding. (Considering (a) the tabulated values of P-bonding as noted above, and (b) the B.E. given in the literature by most researchers, and (3) the various elements available in this system for bonding to $\mathrm{P}$, it is reasonable to conclude that the $\mathrm{P} 2 \mathrm{p}$ peak at $\sim 134 \mathrm{eV}$ is $\mathrm{P}$ bound to $\mathrm{O}$. If $\mathrm{P}$ were bound to one of the various metals or $\mathrm{C}$ it would be $3-5 \mathrm{eV}$ lower in $\mathrm{BE}$. In this instance, the $\mathrm{P} 2 \mathrm{p} \mathrm{BE}$ is easily determined without peak fitting.) The P peak of IL_300C_corr was very low, consistent with Table 4.

The $\mathrm{O}$ 1s data in Fig. 6 were core level spectra collected at a pass energy of $50 \mathrm{eV}$ (our normal "work-a-day PE) to get a qualitative assessment of surface chemistry prior to profiling. 
Results reflect a mixture of $\mathrm{O}$ species that can be related to metal-oxides ( $\mathrm{Mg}-\mathrm{O}$ and $\mathrm{Al}-\mathrm{O}$ ), $\mathrm{P}-\mathrm{O}$, and $\mathrm{C}-\mathrm{O}$ bonding. (The $\mathrm{O} 1 \mathrm{~s}$ could be fit with a complex series of overlapping peaks representing various $\mathrm{C} / \mathrm{O}$ bonds, $\mathrm{O}-\mathrm{Mg}$ bonds, and $\mathrm{O}-\mathrm{P}$ bonds. For this study, it was sufficient to observe that the broad, non-distinct $\mathrm{O} 1 \mathrm{~s}$ spectrum was at a $\mathrm{BE}$ location that corresponded to these various species and the there was ample $\mathrm{O}$ for the amounts of $\mathrm{Mg}, \mathrm{C}, \mathrm{P}, \mathrm{Al}$ present.)

The $\mathrm{C} 1$ s spectrum shows at least three types of C-bonding: C-C at $\sim 284.8 \mathrm{eV}, \mathrm{C}-\mathrm{O}$ at $285-$ $286 \mathrm{eV}$, and carbonate (or some other $\mathrm{O}-\mathrm{C}=\mathrm{O}$ type of carbon species) at $\sim 290 \mathrm{eV}$. For the IL_300C surface, most of the $\mathrm{C}$ is present as the "ubiquitous carbon" that is found on most airexposed metal surfaces $(\mathrm{Co} / \mathrm{CO} /$ hydrocarbons, etc) and $\mathrm{C}-\mathrm{C}$ bound species from the IL. In addition, peak at higher BE $(\sim 289 \mathrm{eV})$ was observed and is attributed to a carbonate species. This feature is widely observed and reported in the literature for $\mathrm{Mg}$ and $\mathrm{Mg}$ alloys. For the IL_300C_corr surface, the peak maximum shifts to higher BE, indicating more C-O species on this surface. Note that the peaks are normalized to the same height: the total amount of $\mathrm{C}$ on the IL_300C_corr surface $62 \%$ less that the total amount of $\mathrm{C}$ on the IL_300C surface. The main difference is that the ratio of C-C to C-O bonds has decreases on the IL_300C_corr surface. For this study, it was determined that a qualitative assessment was adequate to understand the starting surface.

Based on comparisons to tabulated $\mathrm{BE}$ and the literature, the $\mathrm{Mg} 2 \mathrm{p}$ for both the IL_300C and IL_300C_corr surfaces shows primarily $\mathrm{MgO}\left(\right.$ or $\left.\mathrm{Mg}^{2+}\right)$. From the $\mathrm{C} 1 \mathrm{~s}$, it is clear that some Mg-carbonate is also present. The breadth of the $\mathrm{O} 1 \mathrm{~s}$ certainly invites the possibility of $\mathrm{Mg}$ hydroxide. The point is, the starting surface is primarily $\mathrm{MgO}$ for the IL_300C_corr. Likewise, the IL_300C surface is primarily $\mathrm{MgO}$, but the small feature at $\sim 61 \mathrm{eV}$ indicates that some $\mathrm{Mg}$ metal is present (this feature is a palsmon that is only visible when metallic $\mathrm{Mg}$ is present) and 
indeed, one can detect a small shoulder on the low $\mathrm{BE}$ side of the $\mathrm{MgO}$ peak indicating a metal signal.

$\mathrm{Al} 2 \mathrm{p}$ is a very weak signal and suffers further from being in close proximity to another $\mathrm{Mg}$ plasmon feature at slightly lower BE (this plasmon feature is easier to see in the IL_300C spectrum, just as the plasmon was visible in the $\mathrm{Mg} 2 \mathrm{p}$ spectrum).

Chemical composition-depth profiles for IL_300C, IL_300C_corr surfaces were generated using XPS aided by ion-sputtering.Three elements were deconvoluted: $\mathrm{Mg}, \mathrm{Al}$, and $\mathrm{O}$, while other elements were plotted as their total signal with no deconvolution. For $\mathrm{Mg}$, two peaks were used, one for Mg metal (which was trivial to identify due to the presence or absence of the plasmon) and another feature we called $\mathrm{Mg}$ ion, which was the reminder of the signal and is primarily $\mathrm{MgO}$ but certainly has some hydroxide and carbonate. (Note that the small feature at $\sim 61 \mathrm{eV}$ for Mg 2p in Fig. 6 indicates that some Mg-metal is present. This feature is a palsmon that is only visible when metallic Mg is present. Indeed, one can detect a small shoulder on the low $\mathrm{BE}$ side of the $\mathrm{MgO}$ peak indicating a metal signal.) Because the profile data is acquired at a relatively low resolution (to increase data acquisition speed), detailed peak fitting into closely overlapping features is difficult, at best. Likewise, the $\mathrm{Al} 2 \mathrm{p}$ was deconvoluted into $\mathrm{Al}$ ion (primarily $\mathrm{Al}$-oxide) and $\mathrm{Al}$ metal. This deconvolution required fitting three features so that the Mg plasmon could be eliminated. The peak separation of the $\mathrm{Al}$ ion and $\mathrm{Al}$ metal features is wide enough to make their identifications.

Figure 7 shows the composition data for the IL_300C surface up to $800 \mathrm{sec}$ of sputtering. Figure $7 \mathrm{~b}$ shows the zoomed-in profiles for elements in lower concentrations. The final crater depth was measured to be $186 \mathrm{~nm}$ using an optical surface profiler, translating to an average sputtering rate of $\sim 14 \mathrm{~nm} / \mathrm{min}$. While it is understood that the sputtering rate may vary at 
different depth into the surface, the average sputtering rate is used here to estimate the film thickness. Apparently there is a surface layer rich of $\mathrm{P}, \mathrm{O}$, and oxidized metals. The elements seem to be leveled out after $350 \mathrm{sec}$ sputtering, suggesting a maximum film thickness of $\sim 80 \mathrm{~nm}$, which agree well with the TEM observation in Fig. 5.

$\mathrm{Mg}$ (ion), $\mathrm{Al}$ (ion), and $\mathrm{O}(\mathrm{O}-\mathrm{Mg}$ ) all reach their maximum concentrations around 25-35 nm (100-150 sec) deep, where was speculated to be the original alloy surface under TEM (see Fig. 5). This is because, during the treatment process, the rates of chemical reactions were highest at the original alloy surface where the metallic elements, oxygen, and IL elements (e.g., P) are all rich. Inside the conversion coating ( $<350 \mathrm{sec}$ of sputtering), the ratio of $\mathrm{Mg}(\mathrm{ion}) / \mathrm{O}(\mathrm{O}-\mathrm{Mg})$ is higher than one, implying other non-metallic $\mathrm{Mg}$ compounds, e.g., $\mathrm{Mg}_{3}\left(\mathrm{PO}_{4}\right)_{2}$, in addition to $\mathrm{MgO}$. Beyond the $350 \mathrm{sec}$ of sputtering, $\mathrm{MgO}$ seems to be the sole non-metallic $\mathrm{Mg}$ compound. The phosphorus content (primarily metal phosphates as shown in Fig. 6) indicates that the phosphate anions of the IL was actively involved in the conversion film formation. A higher P concentration was observed in the top layer outside the original alloy surface than the second layer inside the original alloy surface. On the other hand, nitrogen was not detected and the role of the ammonium cations of the IL in the conversion film formation is not clear. The existence of multiple carbon bonds $(\mathrm{C}-\mathrm{C}, \mathrm{C}-\mathrm{O}$, and $\mathrm{O}-\mathrm{C}=\mathrm{O})$ suggests that such conversion coating contains organic or organometallic compounds in addition to inorganic metal oxides and phosphates.

The XPS composition depth profile of the surface after the corrosion exposure test (IL_300C_corr) is shown in Fig. 8. The increased oxygen concentration and longer sputtering time to remove the surface layer imply growing surface oxides and hydroxides when attacked by $\mathrm{Cl}^{-}$ions in a salt solution [29]. Since the corroded surface was rough and the crater depth could not the precisely determined by surface profiling, the sputtering rate was not available and the 
thickness of the corroded surface layer could not be estimated. The phosphorus content was not traceable $(<0.1 \%)$ after initial ion sputtering and thus is not shown in the composition profile here. This suggests that the corrosive solution fully dissolved the conversion coating during the 4-hr exposure test. It is interesting to observe no $\mathrm{Zn}$ in the corroded surface film.

Results of TEM and XPS confirmed the formation of a dense conversion coating on the Mg AZ31B alloy surface and further revealed a two-layer structure and the composition of a mixture of metal oxides, metal phosphates, and some carbonaceous compounds.

\section{Conclusions}

This study described a conversion coating for the $\mathrm{Mg}$ AZ31B alloy using a protic ammonium-phosphate IL at $300{ }^{\circ} \mathrm{C}$, above its onset decomposition temperature, and demonstrated significantly improved corrosion resistance. The weak acidic nature of the protic IL eliminates the need of a pretreatment as required by an aprotic IL and preserves the surface morphology (that is otherwise often altered by pretreatments). Potentiodynamic polarization analysis of the IL_300C treated $\mathrm{Mg}$ surface in 1 wt. \% $\mathrm{NaCl}$ solution saturated with $\mathrm{Mg}(\mathrm{OH})_{2}$ exhibited a much stronger passivation behavior compared to the untreated surface or treated by the same IL at room temperature. Oxidation without IL did not provide any improvement on the corrosion resistance. Results clearly demonstrated that it is the combination of IL chemistry and the heat treatment that produced an effective anti-corrosion conversion. Cross-sectional TEM/EDS examination and XPS chemical analysis revealed that the IL_300C conversion coating is a $70-80 \mathrm{~nm}$ thick in a two-layer structure and is composed of metal oxides, metal phosphates, and some carbonaceous compounds. It is believed that the thermal stress during the heat treatment promotes the IL decomposition and the decomposed species then actively reacts 
with the alloy surface to produce phosphates and organic/organometallic compounds, which unites together with the growing oxides to form a dense conversion coating.

\section{Acknowledgements}

The authors thank Drs. M. P. Brady and G.-L. Song from Oak Ridge National Laboratory (ORNL) for technical discussions and D.W. Coffey from ORNL for TEM sample preparation. Research sponsored by the Laboratory Directed Research and Development Program of Oak Ridge National Laboratory. H. H. Elsentriecy acknowledges the postdoctoral fellowship administered jointly by ORNL and ORISE.

Note: This manuscript has been authored by UT-Battelle, LLC, under Contract No. DE-AC05O0OR22725 with the U.S. Department of Energy. The United States Government retains and the publisher, by accepting the article for publication, acknowledges that the United States Government retains a non-exclusive, paid-up, irrevocable, world-wide license to publish or reproduce the published form of this manuscript, or allow others to do so, for United States Government purposes.

\section{References}

[1] B. A. Shaw, Corrosion resistance of magnesium alloys, ASM Handbook, Volume 13A Corrosion: Fundamentals, Testing, and Protection (\#06494G), 2003 ASM International, p. 692-696.

[2] G.-L. Song, A. Atrens, Corrosion mechanisms of magnesium alloys, Advanced Engineering Materials 1 (1999) 11-33.

[3] G.-L. Song, A. Atrens, Understanding magnesium corrosion - a framework for improved alloy performance, Advanced Engineering Materials 5 (2003) 837-858.

[4] G.-L. Song, Recent progress in corrosion and protection of magnesium alloys, Advanced Engineering Materials 7 (2005) 563-586.

[5] G.-L. Song, A. Atrens, Recent insights into the mechanism of magnesium corrosion and research suggestions, Advanced Engineering Materials 9 (2007) 177-183. 
[6] S.V. Lamaka, M.F. Montemor, A.F. Galio, M.L. Zheludkevich, C. Trindade, L.F. Dick, M.G.S. Ferreira, Novel hybrid sol-gel coatings for corrosion protection of AZ31B magnesium alloy, Electrochimica Acta 53 (2008) 4773-4783.

[7] M. Yekehtaz, F. Sittner, R. Ugas-Carrión, S. Flege, J. Brötz, W. Ensinger, Characterization of protective sol-gel coatings on magnesium based on phenyl-triethoxysilane precursor, Thin Solid Films 518 (2010) 5223-5226.

[8] J. Hu, Q. Li, X. Zhong, L. Li, L. Zhang, Organic coatings silane-based for AZ91D magnesium alloy, Thin Solid Films 519 (2010) 1361-1366.

[9] R. Petro, M. Schlesinger, G.-L. Song, Ionic liquid treatments for enhanced corrosion resistance of magnesium-based substrates, Modern Electroplating, Fifth Ed., Ed: M. Schlesinger and M. Paunovic, 2010, John Wiley \& Sons, Inc.

[10] H. H. Elsentriecy, K. Azumi, H. Konno, Improvement in stannate chemical conversion coatings on AZ91 D magnesium alloy using the potentiostatic technique, Electrochimica Acta 53 (2007) 1006-1012.

[11] H. H. Elsentriecy, K. Azumi, H. Konno, Effects of $\mathrm{pH}$ and temperature on the deposition properties of stannate chemical conversion coatings formed by the potentiostatic technique on AZ91 D magnesium alloy, Electrochimica Acta 53 (2008) 4267-4275.

[12] M. F. Montemor, A. M. Simoes, M. J. Carmezim, Characterization of rare-earth conversion films formed on the AZ31 magnesium alloy and its relation with corrosion protection, Applied Surface Science 253 (2007) 6922-6931.

[13] M. F. Montemor, A. M. Simoes, M. G. S. Ferreira, M.J. Carmezim, Composition and corrosion resistance of cerium conversion films on the AZ31 magnesium alloy and its relation to the salt anion, Applied Surface Science 254 (2008) 1806-1814.

[14] D. Hawke, D. L. Albright, A phosphate-permanganate conversion coating for magnesium, Metal Finishing 93 (1995) 34-38.

[15] J. D. Holbrey, K. R. Seddon, Ionic liquids, Clean Products and Processes 1 (1999) 223-236.

[16] M. Forsyth, P. C. Howlett, S. K. Tan, D. R. MacFarlane, N. Birbilis, An ionic liquid surface treatment for corrosion protection of magnesium alloy AZ31, Electrochemical and SolidState Letters 9 (2006) B52-B55.

[17] N. Birbilis, P. C. Howlett, D. R. MacFarlane, M. Forsyth, Exploring corrosion protection of Mg via ionic liquid pretreatment, Surface \& Coatings Technology 201 (2007) 4496-4504.

[18] J. Sun, P. C. Howlett, D. R. MacFarlane, J. Lin, M. Forsyth, Synthesis and physical property characterisation of phosphonium ionic liquids based on $\mathrm{P}(\mathrm{O})_{2}(\mathrm{OR})_{2}{ }^{-}$and $\mathrm{P}(\mathrm{O})_{2}(\mathrm{R})_{2}{ }^{-}$anions with potential application for corrosion mitigation of magnesium alloys, Electrochimica Acta 54 (2008) 254-260. 
[19] M. Forsyth, W. C. Neil, P. C. Howlett, D. R. Macfarlane, B. R.W. Hinton, N. Rocher, T. F. Kemp, M. E. Smith, New insights into the fundamental chemical nature of ionic liquid film formation on magnesium alloy surfaces, Applied Materials and Interfaces 1 (2009) 10451052.

[20] J. Efthimiadis, W. C. Neil, A. Bunter, P. C. Howlett, B. R. W. Hinton, D. R. MacFarlane, M. Forsyth, Potentiostatic control of ionic liquid surface film formation on ZE41 magnesium alloy, ACS Applied Materials and Interfaces 2 (2010) 1317-1323.

[21] P. C. Howlett, T. Khoo, G. Mooketsi, J. Efthimiadis, D. R. MacFarlane, M. Forsyth, The effect of potential bias on the formation of ionic liquid generated surface films on $\mathrm{Mg}$ alloys, Electrochimica Acta 55 (2010) 2377-2383.

[22] J.-A. Latham, P. C. Howlett, D. R. MacFarlane, M. Forsyth, Electrochemical reactivity of trihexyl(tetradecyl)phosphonium bis(2,4,4-trimethylpentyl)phosphinate ionic liquid on glassy carbon and AZ31 magnesium alloy, Electrochimica Acta 56 (2011) 5328-5334.

[23] J. Qu, P. J. Blau, S. Dai, H. M. Luo, H. M. Meyer III, J. J. Truhan, Tribological characteristics of aluminum alloys against steel lubricated by imidazolium and ammonium ionic liquids, Wear 267(5-8) (2009) 1226-1231.

[24] J. Qu, M. Chi, H. M. Meyer III, P. J. Blau, S. Dai, H. Luo, Nanostructure and composition of tribo-boundary films formed in ionic liquid lubrication, Tribology Letters 43(2) (2011) 205-211.

[25] J. Qu, D. G. Bansal, B. Yu, J. Howe, H. Luo, S. Dai, H. Li, P. J. Blau, B. G. Bunting, G. Mordukhovich, D. J. Smolenski, Anti-wear performance and mechanism of an oil-miscible ionic liquid as a lubricant additive, ACS Applied Materials \& Interfaces 4 (2) (2012) 9971002.

[26] H. H. Elsentriecy, H. Luo, H. M. Meyer III, L. L. Grado, J. Qu, Effects of pretreatment and process temperature of a conversion coating produced by an aprotic ammonium-phosphate ionic liquid on magnesium corrosion protection, Electrochimica Acta 123 (2014) 58-65.

[27] J. F. Moulder, W. F. Stickle, P. E. Sobol, and K. Bomben (J. Chastain, editor), Handbook of X-ray Photoelectron Spectroscopy $3^{\text {rd }}$ ed. Perkin-Elmer Corporation (Physical Electronics), 1995.

[28] N. Ikeo, Y. Iijima, N. Nimura, M. Sigematsu, T. Tazawa, S. Matsumoto, K. Kojima, and Y. Nagasawa, Handbook of X-ray Photoelectron Spectroscopy, JEOL, 1991.

[29] N. Hara, Y. Kobayashi, D. Kagaya, N. Akao, Formation and breakdown of surface films on magnesium and its alloys in aqueous solutions, Corrosion Science 49 (2007) 166-175. 


\section{Tables}

Table 1. Chemical composition of AZ31B alloy in wt. \%.

\begin{tabular}{lllllll}
\hline Element & $\mathrm{Mg}$ & $\mathrm{Al}$ & $\mathrm{Zn}$ & $\mathrm{Mn}$ & $\mathrm{Fe}$ & $\mathrm{Zr} / \mathrm{Nd} / \mathrm{Cu} / \mathrm{Ni}$ \\
\hline Wt. \% & 95.64 & 3.03 & 1.06 & 0.25 & 0.01 & $<0.01$ \\
\hline
\end{tabular}

Table 2. List of Mg samples.

\begin{tabular}{ll}
\hline Surface treatment & Sample code \\
\hline As polished without treatment & As polished \\
\hline As polished at $300{ }^{\circ} \mathrm{C}$ for 7 minutes (No IL) & As polished_300C \\
\hline Treated by IL at $300{ }^{\circ} \mathrm{C}$ for 7 minutes & IL_300C \\
\hline IL_300C $+4-\mathrm{hr}$ immersion in $1 \mathrm{wt} . \% \mathrm{NaCl}$ & IL_300C_corr \\
saturated with $\mathrm{Mg}(\mathrm{OH})_{2}$ & \\
\hline Treated by IL at $\mathrm{RT}$ for 24 hours & IL_RT \\
\hline
\end{tabular}


Table 3. Electrochemical corrosion parameters deduced from polarization curves. $\mathrm{E}_{\text {corr }}$ : corrosion potential; $\mathrm{I}_{\text {corr }}$ : corrosion current density; $\mathrm{E}_{\mathrm{pit}}$ : pitting potential; $\mathrm{E}_{\mathrm{pit}}-\mathrm{E}_{\mathrm{corr}}$ : pit nucleation resistance.

\begin{tabular}{lcccc}
\hline Sample & $\begin{array}{c}\mathrm{E}_{\text {corr }}(\mathrm{V} \text { vs. } \\
\mathrm{Ag} / \mathrm{AgCl})\end{array}$ & $\mathrm{I}_{\text {corr }}\left(\mu \mathrm{A} / \mathrm{cm}^{2}\right)$ & $\begin{array}{c}\mathrm{E}_{\text {pit }}(\mathrm{V} \text { vs. } \\
\mathrm{Ag} / \mathrm{AgCl})\end{array}$ & $\begin{array}{c}\mathrm{E}_{\text {pit }}-\mathrm{E}_{\text {corr }}(\mathrm{mV} \text { vs. } \\
\mathrm{Ag} / \mathrm{AgCl})\end{array}$ \\
\hline As polished [26] & -1.411 & 195.843 & $\mathrm{NA}$ & $\mathrm{NA}$ \\
\hline As polished_300C & -1.479 & 131.638 & $\mathrm{NA}$ & $\mathrm{NA}$ \\
\hline IL_300C & -1.437 & 13.566 & -1.31 & 127 \\
\hline IL_RT & -1.451 & 25.973 & -1.427 & 24 \\
\hline
\end{tabular}

Table 4. Surface composition (at.\%) (survey scan).

\begin{tabular}{llllllll}
\hline & $\mathrm{Mg}$ & $\mathrm{Al}$ & $\mathrm{Zn}$ & $\mathrm{O}$ & $\mathrm{C}$ & $\mathrm{P}$ & $\mathrm{N}$ \\
\hline IL_300C & 19.5 & 0.8 & 0.0 & 33.8 & 41.9 & 2.9 & 0.4 \\
\hline IL_300C_corr & 34.4 & 0.6 & 0.0 & 48.9 & 16.0 & 0.1 & 0.0 \\
\hline
\end{tabular}




\section{Figure captions}

Figure 1. Synthesis scheme and molecular structure of the protic IL [ $\left.\mathrm{N}_{888} \mathrm{H}\right][\mathrm{DEHP}]$.

Figure 2. TGA curves of $\left[\mathrm{N}_{888} \mathrm{H}\right][\mathrm{DEHP}]$.

Figure 3. Potentiodynamic polarization curves of (a) comparison of untreated [21] and IL-treated $\mathrm{Mg}$ AZ31B alloy measured in $1 \mathrm{wt} \% \% \mathrm{NaCl}$ saturated with $\mathrm{Mg}(\mathrm{OH})_{2}$ and (b) showing good repeatability.

Figure 4. SEM images of Mg AZ31B surfaces before (a) [21] and after (b) IL treatment at 300 ${ }^{\circ} \mathrm{C}$.

Figure 5. Cross-sectional TEM image and EDS elemental maps of the IL conversion coating (formed at $300{ }^{\circ} \mathrm{C}$ ) on the $\mathrm{Mg} \mathrm{AZ31B}$ alloy surface.

Figure 6. XPS core level spectra of IL_300C treated surfaces before (blue) and after (red) the 4hr exposure corrosion test.

Figure 7. XPS composition depth profile of the IL_300C treated surface before corrosion testing; $7 \mathrm{~b}$ showing the zoomed-in profiles for elements in lower concentrations.

Figure 8. XPS composition depth profile of the IL_300C treated surface after the 4-hr exposure corrosion test (IL_300C_corr); 8b showing the zoomed-in profiles for elements in lower concentrations. 


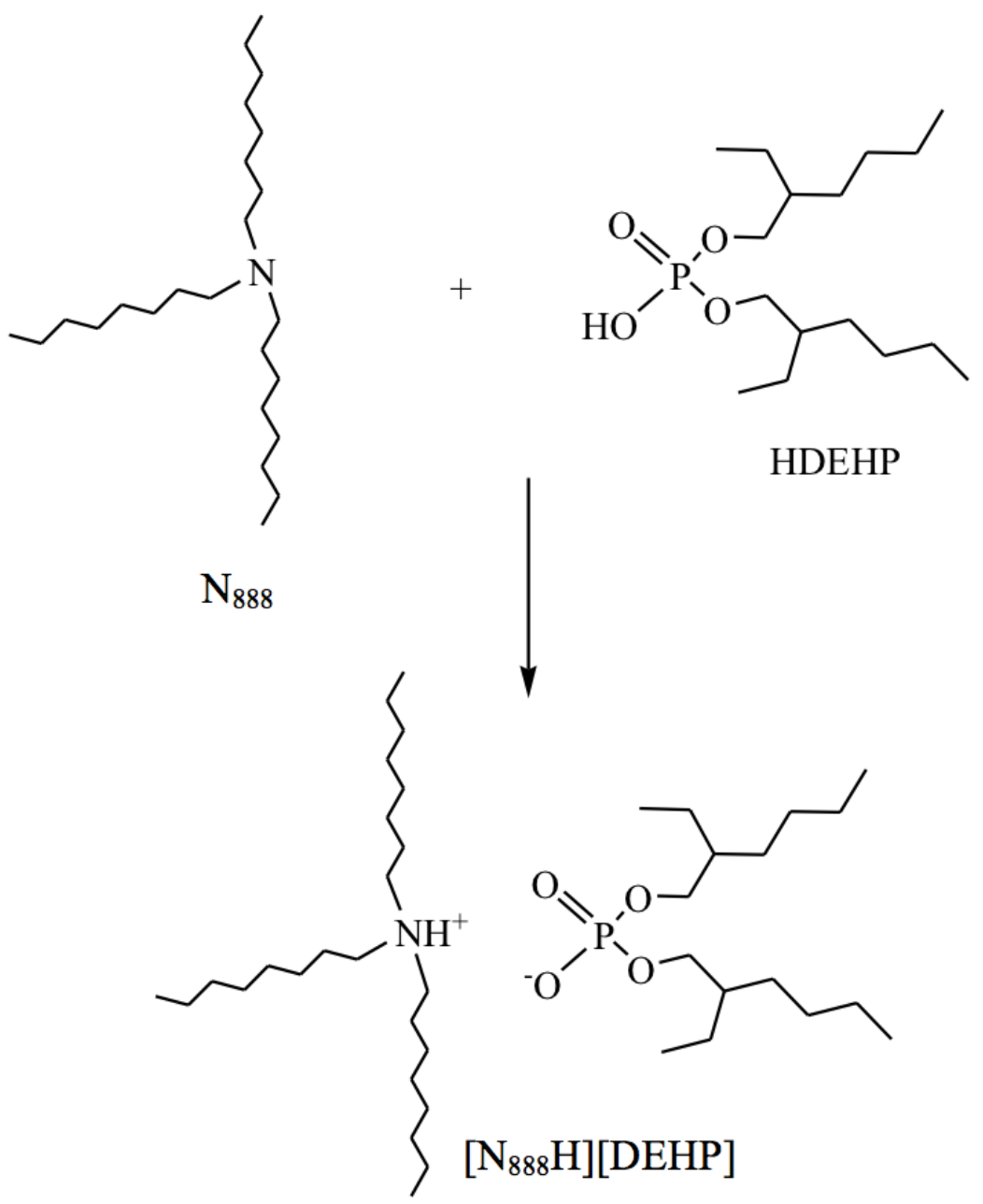

Figure 1. Synthesis scheme and molecular structure of the protic IL [ $\left.\mathrm{N}_{888} \mathrm{H}\right][\mathrm{DEHP}]$. 


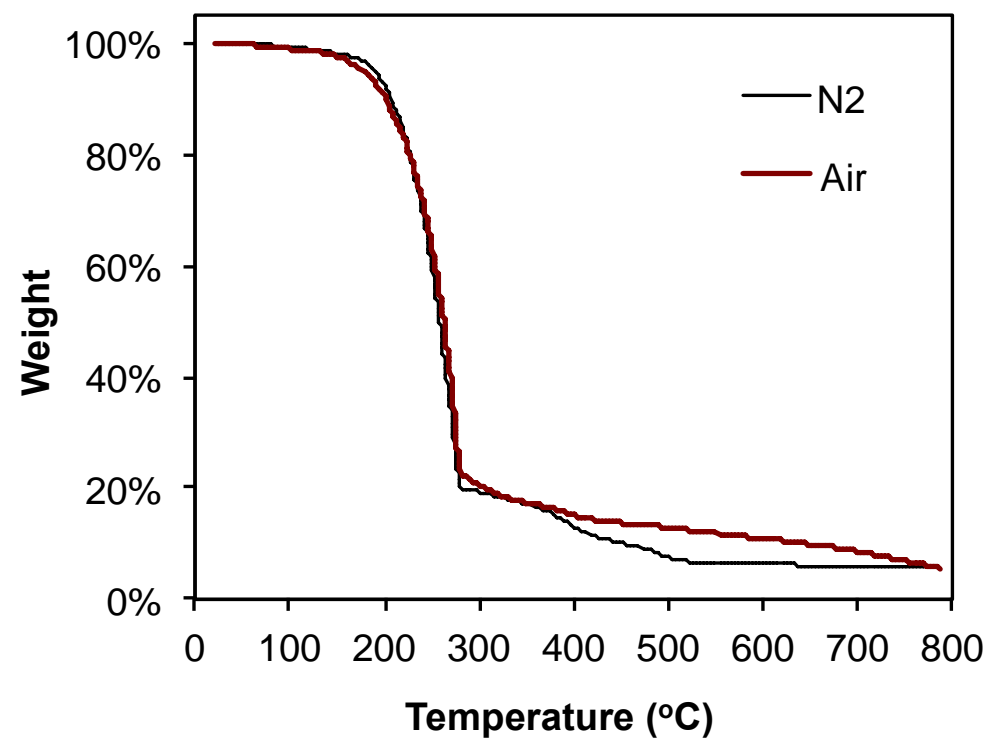

Figure 2. TGA curves of $\left[\mathrm{N}_{888} \mathrm{H}\right][\mathrm{DEHP}]$. 

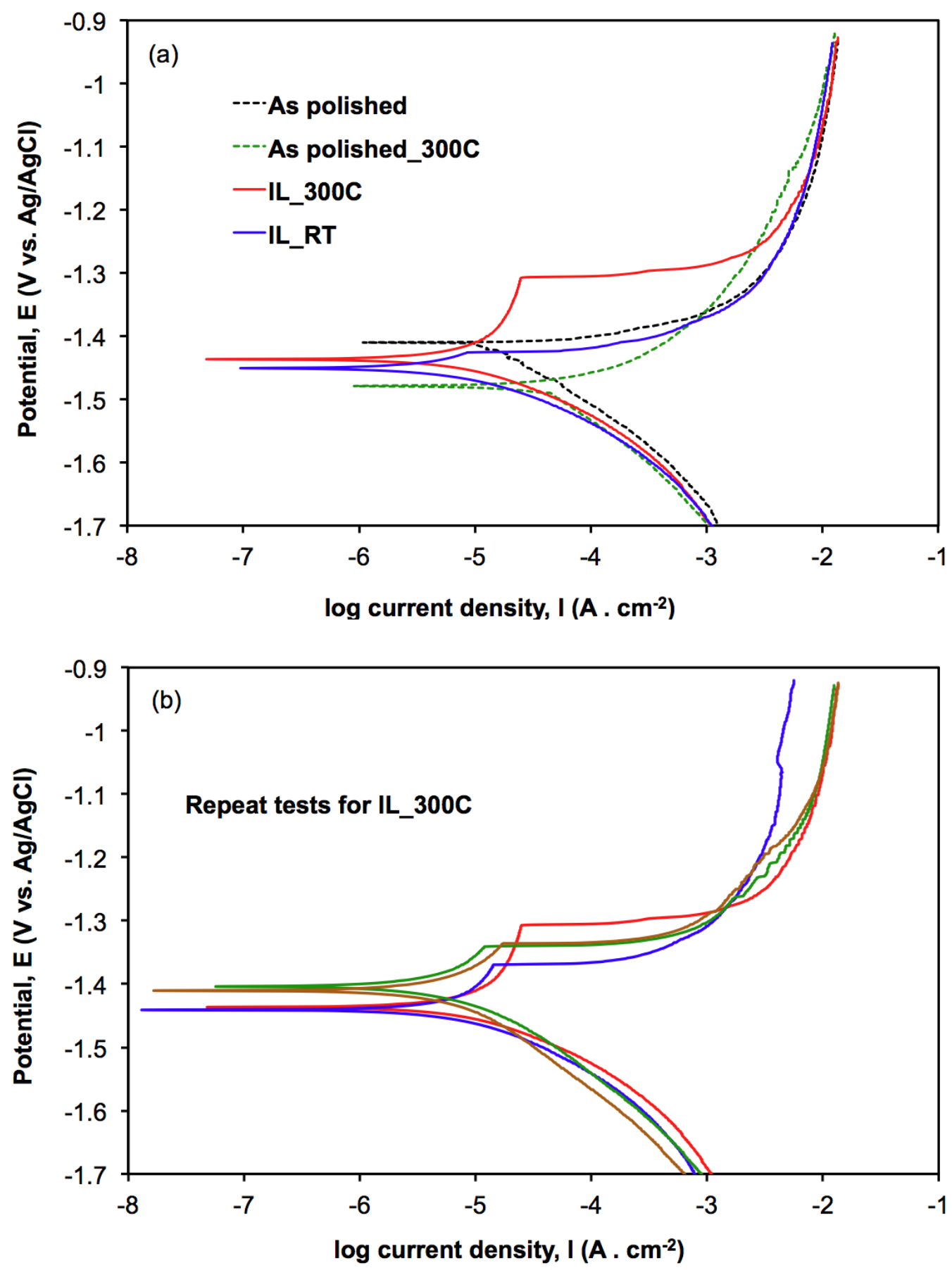

Figure 3. Potentiodynamic polarization curves of (a) comparison of untreated [21] and IL-treated $\mathrm{Mg}$ AZ31B alloy measured in $1 \mathrm{wt} . \% \mathrm{NaCl}$ saturated with $\mathrm{Mg}(\mathrm{OH})_{2}$ and (b) showing good repeatability. 

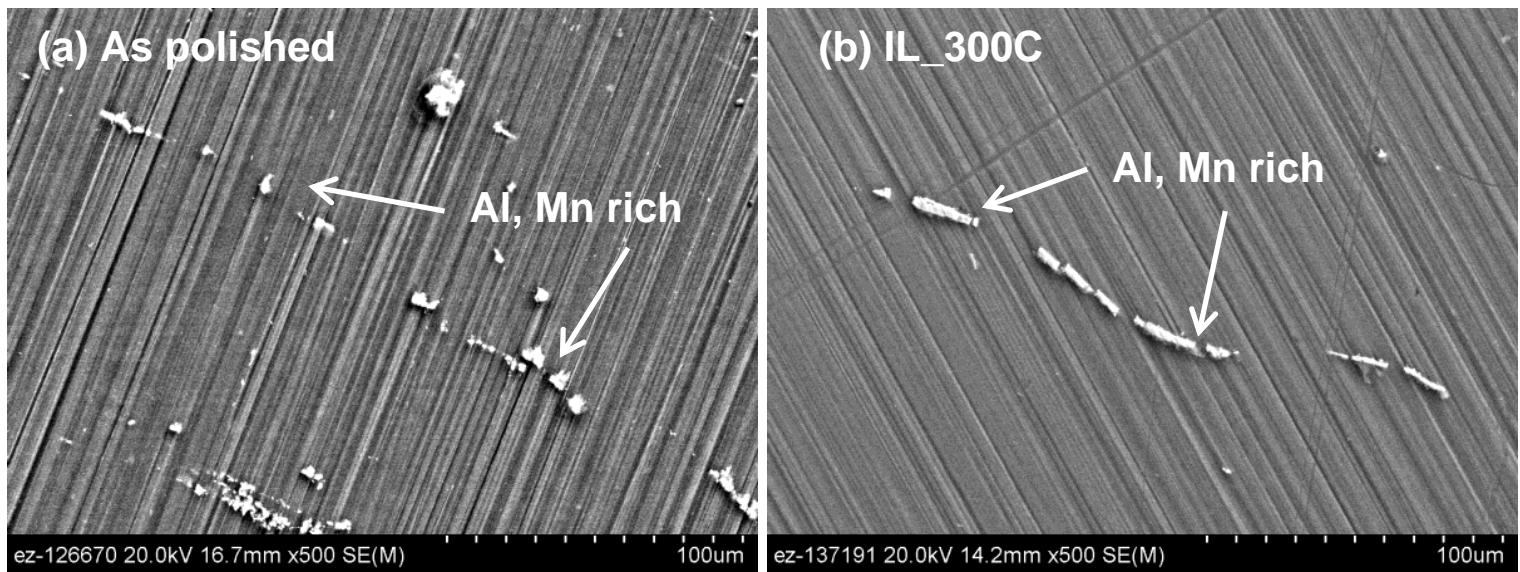

Figure 4. SEM images of Mg AZ31B surfaces before (a) [21] and after (b) IL treatment at 300 ${ }^{\circ} \mathrm{C}$ showing little morphology change. 

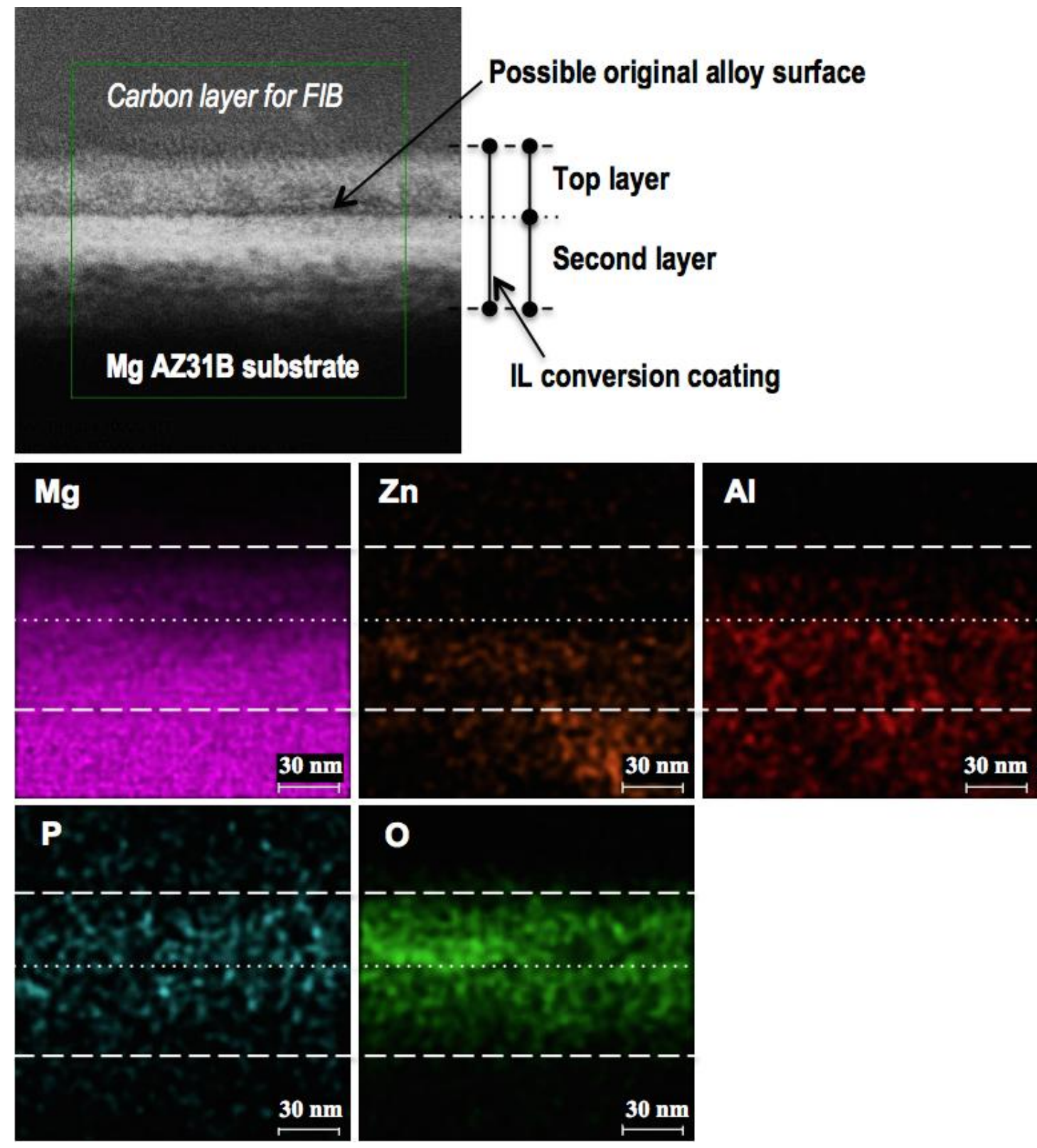

Figure 5. Cross-sectional TEM image and EDS elemental maps of the IL conversion coating on the AZ31B $\mathrm{Mg}$ alloy surface formed at $300^{\circ} \mathrm{C}$. 

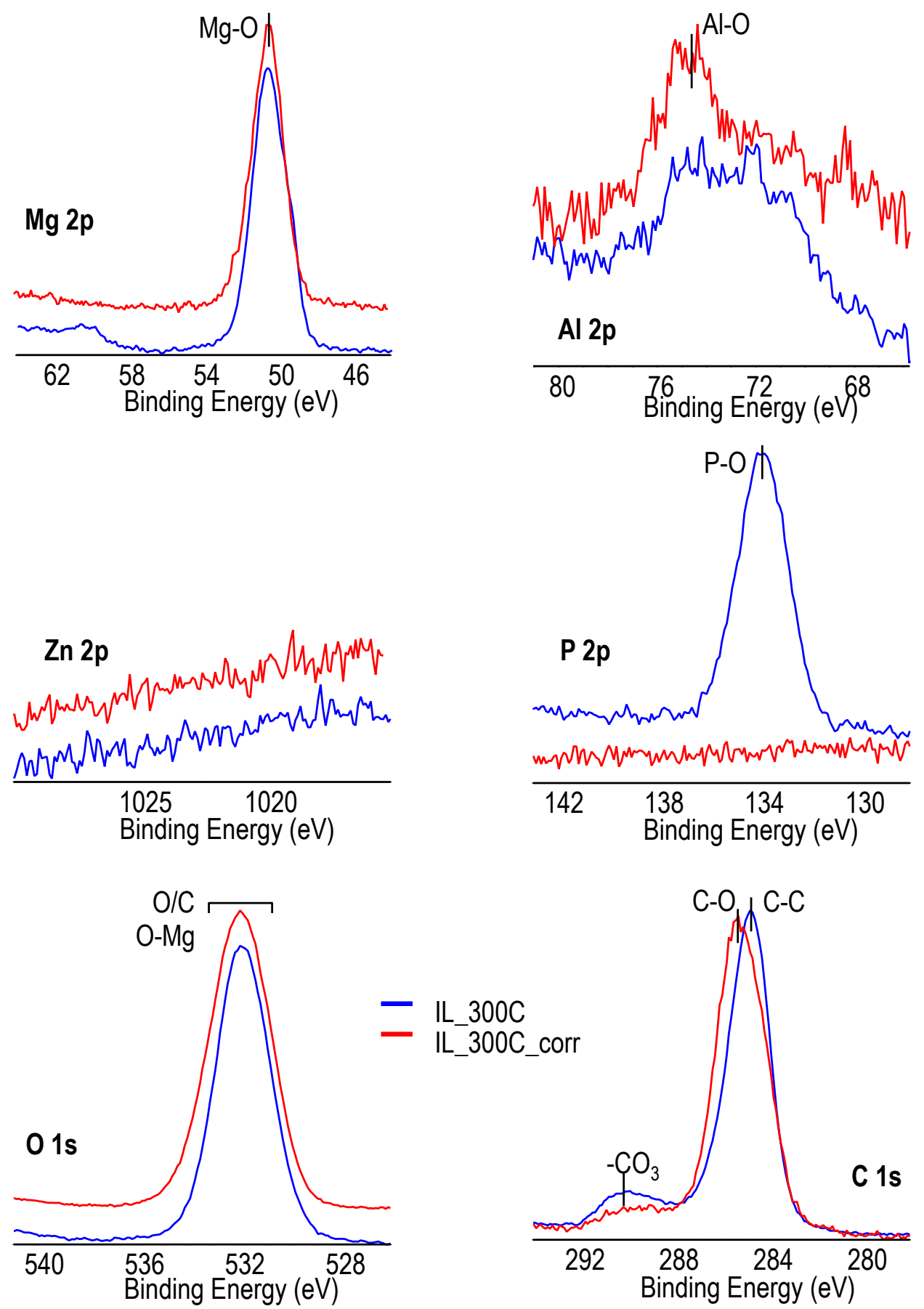

Figure 6. XPS core level spectra of IL_300C treated surfaces before (blue, IL_300C) and after (red, IL_300C_corr) the 4-hr exposure corrosion test. 

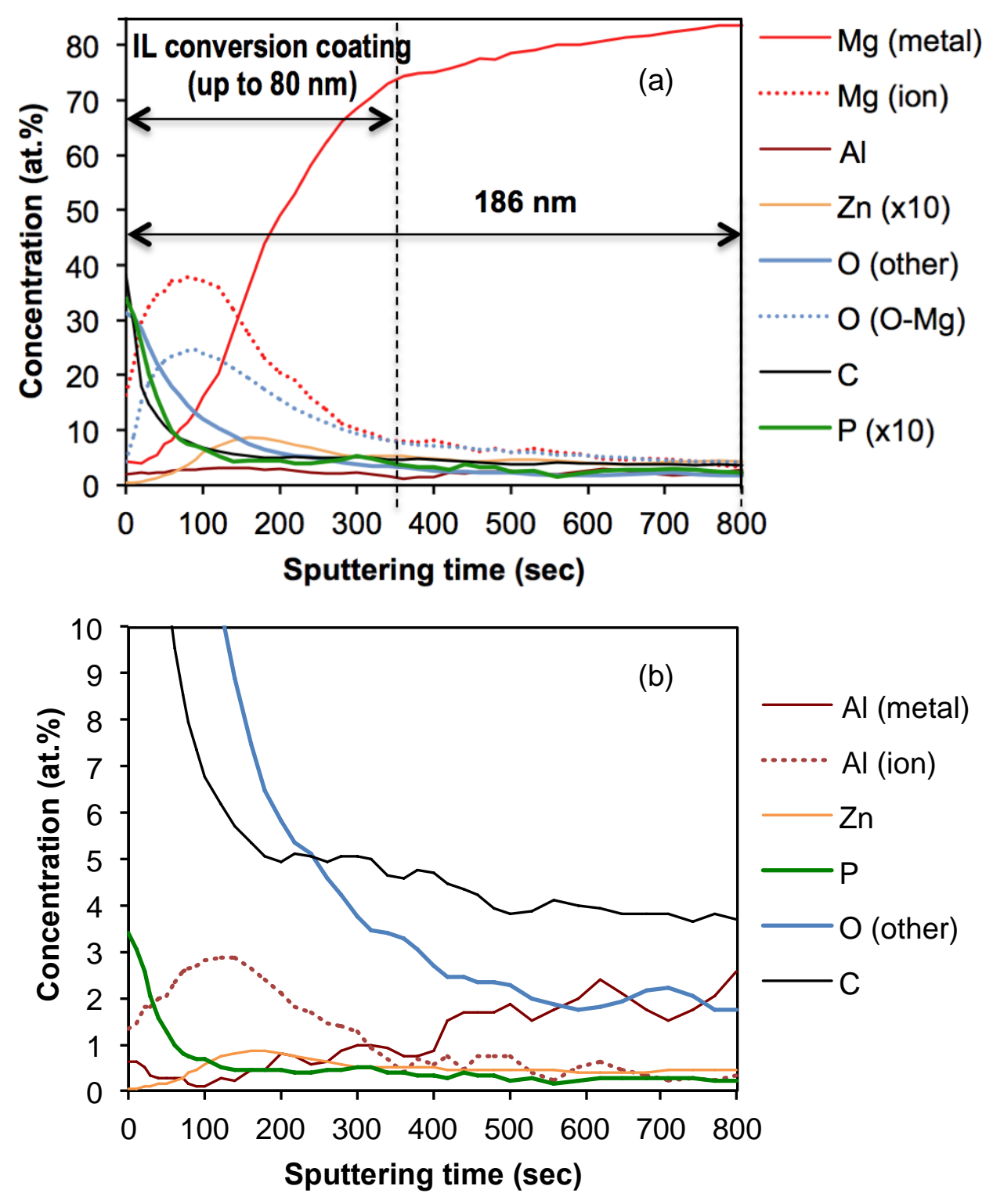

Figure 7. XPS composition depth profile of the IL_300C treated surface before corrosion testing; $7 \mathrm{~b}$ showing the zoomed-in profiles for elements in lower concentrations. 

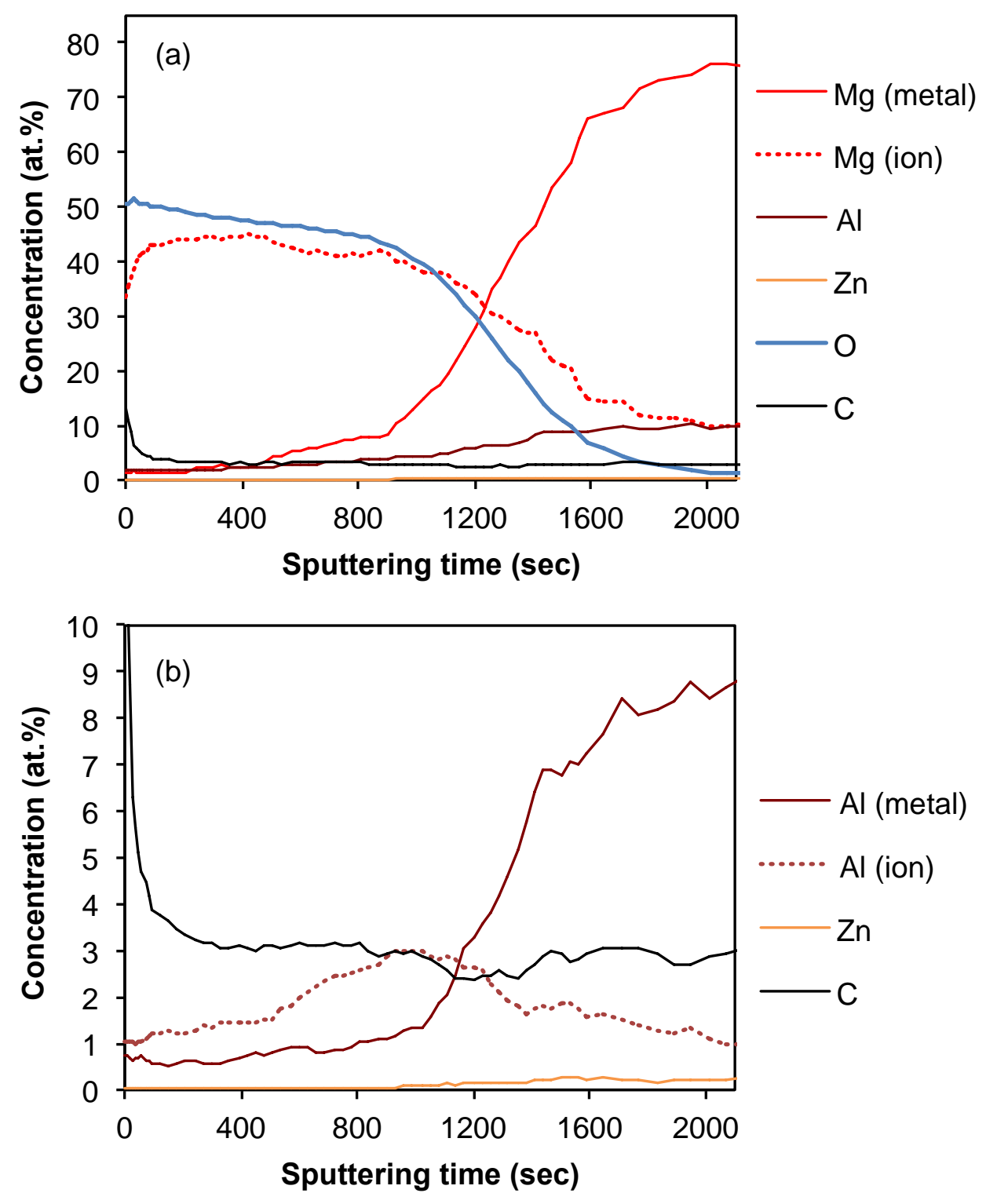

Figure 8. XPS composition depth profile of the IL_300C treated surface after the 4-hr exposure corrosion test (IL_300C_corr); 8b showing the zoomed-in profiles for elements in lower concentrations. 